\title{
Influence of Acute Bouts of Exercise on Blood Glucose in Type 2 Diabetic Patients, as Measured by Continuous Glucose Monitoring Systems
} Elisabetta Bacchi, Carlo Negri, Enzo Bonora and Paolo Moghetti*

Unit of Endocrinology, Diabetes and Metabolism, University and Azienda Ospedaliera Universitaria Integrata of Verona, Verona, Italy

\begin{abstract}
Literature data indicate that the effect on blood glucose levels of a single bout of exercise may persist up to 48-h after cessation of exercise. Regular exercise improves insulin sensitivity and blood glucose control in subjects with type 2 diabetes and is considered a key element in the management of this condition. However, adaptive responses to exercise are altered in diabetic subjects and medications used in these patients may cause inappropriate insulin levels for the concurrent blood glucose concentrations, with a possible increase in risk for hypoglycaemia. Recently, the development and clinical availability of systems for the continuous monitoring of glucose (continuous glucose monitoring system, CGMS), have made it possible to continuously record blood glucose levels for several days in real life conditions, showing that possible differences in blood glucose levels of these individuals may occur during and after a single bout of exercise, depending on the characteristics of the physical activity. In particular, differences between aerobic vs resistance exercise and between low-intensity vs high-intensity exercise have been reported. However, there are only a few, small heterogeneous studies on this topic, and results are to some extent discordant, limiting any conclusions.

Further research on this issue is needed before we can reach clear conclusions. In particular, the role of differences in frequency, duration, intensity, type and timing of exercise needs to be carefully investigated. Hopefully, this information will assist clinicians and exercise specialists in designing personalized exercise programmes and strategies aimed at optimally improving glucose control of type 2 diabetic patients, also limiting the risk for hypoglycaemia. In this article, we review the literature regarding the acute effect of different types of exercise on glucose levels, as measured by CGMS, in subjects with type 2 diabetes.
\end{abstract}

Keywords: Exercise; CGMS; Type 2 diabetes; Aerobic training; Resistance training; Blood glucose

\section{Introduction}

Regular exercise training improves insulin sensitivity and blood glucose control in subjects with type 2 diabetes [1] and is considered a key element in the management of this condition [2]. Furthermore, regular exercise in these subjects offers a number of additional benefits, such as improved body composition with increased skeletal muscle mass and decreased fat mass, especially ectopic and abdominal fat $[3,4]$, improved blood pressure and lipid profile, increased cardiorespiratory fitness [5], as well as increased physical capacity and well-being, even in older people [6].

Both aerobic and resistance exercise training may be helpful in these patients. It is noteworthy that these exercise modalities share some general effects, but differ in their specific characteristics and effects. Aerobic training, such as walking or jogging, involves repetitive and rhythmic contraction of large muscle groups, promoting cardiorespiratory fitness, whereas resistance training, such as weightlifting, typically engages relatively slow, high force contractions, promoting musculoskeletal fitness and stimulating the increase in muscle cross-sectional area. A single bout of physical exercise has an insulin-like effect, enhancing glucose uptake even in the presence of insulin resistance [7]. The effect on glucose tolerance of a single session of exercise may persist for periods from 2-h to 48-h after cessation of exercise [7-9], both in diabetic and non diabetic patients.

In healthy subjects, the coordination and integration of the sympathetic nervous and endocrine systems play a crucial role in the maintenance of blood glucose levels at the physiological levels during and after physical exercise [10]. Although muscle contraction may substantially increase glucose uptake in skeletal muscle, glucose levels are generally maintained within the narrow physiological range through liver gluconeogenesis and glycogenolysis, and mobilization of alternate fuels. These mechanisms are altered in subjects with diabetes mellitus, who have an impaired capacity to regulate glucose levels, and anti-diabetic medications may further contribute to this alteration, as drug-modulated insulin levels may be inappropriate for the concurrent blood glucose concentrations during exercise.

In older studies, glucose changes during and after exercise were measured by finger-stick blood glucose measurement or by more precise laboratory assays on blood samples, at standardized time points. However, both these approaches greatly limit the possibility of monitoring blood glucose changes over prolonged periods in real life conditions. In the last few years, a new tool, the continuous glucose monitoring system (CGMS), has been validated and is increasingly used in clinical practice, as it allows physicians and researchers to continuously monitor glucose levels in real life conditions, including

*Corresponding author: Paolo Moghetti, Unit of Endocrinology, Diabetes and Metabolism, Department of Medicine, University of Verona, Piazzale Stefani, 1, 37126 Verona, Italy, Tel: +39 045 8123110; Fax: +39045 8027314; E-mail: paolo.moghetti@univr.it

Received August 21, 2013; Accepted November 16, 2013; Published November 21, 2013

Citation: Bacchi E, Negri C, Bonora E, Moghetti P (2013) Influence of Acute Bouts of Exercise on Blood Glucose in Type 2 Diabetic Patients, as Measured by Continuous Glucose Monitoring Systems. J Diabetes Metab 4: 311 doi:10.4172/2155-6156.1000311

Copyright: $\odot 2013$ Bacchi E, et al. This is an open-access article distributed under the terms of the Creative Commons Attribution License, which permits unrestricted use, distribution, and reproduction in any medium, provided the original author and source are credited. 
physical activity, for several consecutive days $[11,12]$. In this article we review the literature regarding the acute effect of exercise on glucose control in subjects with type 2 diabetes, as measured by CGMS.

\section{Exercise for Type 2 Diabetes}

The chronic beneficial effect of exercise on metabolic alterations of individuals with type 2 diabetes is attributed to the cumulative effects of successive bouts of exercise. Therefore, it is recommended that exercise be performed at least 3-4 times per week. Interestingly, recent RCTs showed that both aerobic and resistance exercise may reduce $\mathrm{HbAlc}$ levels in type 2 diabetes patients $[3,13,14]$, also suggesting that their combination may be more effective $[13,14]$.

The recent American College of Sport Medicine (ACSM) and American Diabetes Association (ADA) guidelines for exercise in diabetes recommend performing at least 150 minutes per week of moderate to vigorous aerobic exercise, at least 3 days a week, with no more than 2 consecutive days between single bouts of exercise [2]. Specifically, aerobic exercise should be at least of moderate intensity, corresponding approximately to $40-60 \%$ of heart rate reserve (HRR) or maximal oxygen uptake $\left(\mathrm{VO}_{2 \max }\right)$. More benefit may be derived from vigorous exercise training, with an intensity $>60 \%$ of HRR. In addition, according to ACSM/ADA recommendations, type 2 diabetic patients should also undertake moderate to vigorous resistance training at least 2-3 times a week, using weight machines and free weights, including 5-10 exercises involving the major muscle groups (upper and lower body, core). Resistance exercise training should be moderate (50\% of 1 repetition maximum, $1-\mathrm{RM})$ or vigorous $(75-80 \%$ of $1-\mathrm{RM})$, with completion of 10-15 repetitions to near fatigue per set, whereas very strenuous strength exercise ( $>85 \%$ 1-RM) is generally not recommended for these subjects, especially for those with hypertension. For optimal resistance training three to four sets should be performed. ACSM/ ADA guidelines highlight the recommendation that initial instruction and periodic supervision by a qualified exercise trainer be guaranteed, particularly for resistance training programmes [2].

It is noteworthy that several factors may influence fuel utilization during exercise. The intensity and duration of exercise are recognized key factors in affecting blood glucose levels. However, it remains unclear whether the acute effect of a single bout of exercise on blood glucose may also differ according to the exercise type. To improve our knowledge about the acute effect of exercise on blood glucose and to enhance our ability to prescribe exercise as an effective strategy for optimizing glucose control, more information is needed about the influence of different characteristics of exercise, such as type, duration, intensity, or timing of exercise programmes, on blood glucose levels, during and after the exercise sessions.

\section{Continuous Glucose Monitoring System}

CGMS provides an estimated value of blood glucose by measuring interstitial glucose and using mathematical algorithms. With the currently available devices a new measurement is available every 3-5 minutes, for several days.

Each device comprises a sensor, a transmitter and a receiver. In order to generate the blood glucose reading, the system calibrates the sensor data against capillary blood glucose measurements, carried out at least one to three times a day. A physiological time lag for interstitial glucose to equilibrate with blood glucose exists, and this difference is most marked at time of rapid changes in blood glucose. Advances in sensor technology have reduced this time lag to around 10-15 minutes
[15]. The glucose level displayed by the monitor is thus an estimate of blood glucose and is an average level derived from data measured over the preceding 1 to 5 minutes [12].

Currently, there are two different types of devices. Most of the systems in clinical usage employ a sensor with an enzyme tipped electrode which is placed into the interstitial fluid, usually of the abdomen wall. The enzyme catalyses oxidation of glucose and this process generates an electrical current in the electrode. This current is transformed into a signal, which is transmitted wirelessly from the sensor to the receiver.

An alternative device uses a microdialysis system to sample interstitial fluid for direct measurement of glucose. In this system a microdialysis fiber (length $2 \mathrm{~cm}$ ) is inserted subcutaneously into the periumbelical region and then connected to a portable apparatus (weight about $250 \mathrm{~g}$ ) and two plastic bags (one for the buffer reservoir and the other for waste products). The whole apparatus is contained in a small wearable pouch and worn with a belt. This system is considerably more cumbersome, limiting its acceptability and the possibility of using it in some exercise conditions.

A comparison of several modern CGMS showed that the clinical accuracy of the available devices is similar during euglycemia, although some of them may work better during hypoglycaemia [12]. In general, performance of CGMS may be lower when glucose levels are changing rapidly or in conditions of hypoglycemia.

As specifically regards the accuracy of CGMS devices during exercise, data are limited. A study assessed the accuracy of a modern CGMS (Medtronic Minimed ${ }^{\circledR}$ ) in 50 children and adolescents with type 1 diabetes, both during an exercise session ( $75 \mathrm{~min}$ on a treadmill, 153 CGMS-reference pairs) and in non-exercise conditions (944 pairs) [16]. As a whole, about two thirds of pairs met the ISO criteria, with similar results during exercise and at other times.

Recently, this issue was assessed in pregnant women with type 1 diabetes, performing 55 min of brisk walking on a treadmill [17]. This study showed that, comparing the results of the current-generation Freestyle Navigator ${ }^{\circledR}$ sensor with the corresponding reference glucose concentrations, CGMS accuracy was significantly lower during exercise. The relative absolute difference between paired sensor and reference glucose values was $18.4 \%$ vs. $11.8 \%$ at rest. These differences remained significant also when correcting for the relative rate of change in plasma glucose levels. In addition, analysis by glucose range showed lower accuracy during hypoglycemia for both sedentary and exercise conditions. Using error grid analysis, which estimates whether inaccuracy of glucose measurements may potentially lead to inappropriate treatment, $96 \%$ of CGMS values were clinically safe under resting conditions compared with $87 \%$ during exercise [17].

The concordance of CGMS and self monitoring of blood glucose (SMBG) was recently assessed in patients with type 2 diabetes, during daily activities and two different exercise sessions [11]. Agreement between SMBG and CGMS was lower during exercise, but more than $90 \%$ of the readings were similar. Nevertheless, it should be borne in mind that CGMS may work even better that traditional SMBG, at least in the normal and elevated glucose ranges [18]. The Kovatchev group analysed data pairs collected with CGMS and SMBG and compared these data with glucose reference values, by error grid analysis: the "clinically accurate," "benign errors," and "clinical errors" were $92.7 \%$, $3.7 \%$, and $3.6 \%$ for CGMS vs. $86.8 \%, 8.7 \%$, and $4.5 \%$ for SMBG [18]. However, in the hypoglycemic range SMBG was more accurate. 
As regards device accuracy when glucose levels are rapidly changing, a recent study compared one modern CGMS (Paradigm ${ }^{\circledR}$ 722 Real-Time) and reference glucose values in response to OGTT [19]. In this study there were increased mismatches and lag times between reference and CGMS values after oral glucose, most notably during the initial phase of rapid increase in glucose levels. CGMS underestimated peak blood glucose by an average of $2.7 \mathrm{mM}$, and there was a peak blood glucose time lag of about $20 \mathrm{~min}$.

Currently, the CGMS makes it possible to record the glucose profile of an individual in real life conditions for up to 5-7 days. However, a recent study showed that, with some devices, CGMS accuracy may not deteriorate over 9 days of wear [19]. The data can be easily downloaded by a PC and analyzed, to evaluate the effects on glucose levels of several factors, such as food, drug timing and exercise. Although physicians and researchers must be aware of the limitations of these devices, CGMS currently represents a novel and irreplaceable tool for prolonged assessment over time of glucose behaviour in a real life setting.

\section{Differences in the Acute Effect of Exercise on Glucose Control: Analysis of Blood Glucose Levels During the Exercise Session}

A few small studies have evaluated the acute effect of exercise on blood glucose levels in subjects with type 2 diabetes, by CGMS. These studies cannot be easily compared as their designs were very heterogeneous, especially in terms of intensity and type of exercise (Table 1).

We have recently assessed the acute effect on blood glucose of a single 60 min bout of exercise in 25 non-insulin treated type 2 diabetes patients, randomized to aerobic or resistance exercise training for 4 months in the RAED2 trial [20]. In these patients, glucose monitoring was carried out during an exercise session and the following 48-h period, under free-living conditions. Interestingly, although the aerobic and the resistance training induced similar long-term improvements in HbA1c levels [3], the effect of a single bout of exercise differed between groups. A comparison of the glucose area under the curve (AUC) during the $60 \mathrm{~min}$ exercise session and the corresponding time of the non-exercise day in the two exercise groups showed that blood glucose levels were lower during the exercise period in the aerobic training group, but not in the resistance training group.

Van Dijk et al. carried out a series of studies on this topic. In a first study, Praet et al. [21] assessed the effects of an acute bout of moderate intensity leg resistance exercise followed by high-intensity interval exercise on the subsequent 24 -h blood glucose profile in 11 insulintreated type 2 diabetic patients, under free-living conditions. These subjects performed an initial procedure of 5-min cycling on a bicycle ergometer at $40 \%$ of their individual Wmax, followed by two sets of 10 repetitions on three resistance exercise machines targeting the upper body, to provide a whole-body warm-up. Thereafter, the resistance exercise session targeted the legs, with two sets of 10 repetitions on the horizontal leg-press machine and two sets of 10 repetitions on the legextension machine, at $50 \%$ of the individual $1 \mathrm{RM}$, with approximately 2 min of rest between sets. Resistance exercise was followed by four bouts of 30-s high-intensity interval exercise on a bicycle ergometer, alternated with $60 \mathrm{~s}$ of $15-\mathrm{W}$ recovery. The total training regimen required approximately $45 \mathrm{~min}$ to be completed. These authors reported that glucose levels declined during exercise and remained lower for approximately $3 \mathrm{~h}$ after cessation of training.
In a subsequent study they compared the impact on blood glucose levels of a single bout of moderate intensity aerobic or resistance training, vs non exercise, in 30 subjects with type 2 diabetes treated with either insulin or oral hypoglycemic agents [22]. A group of subjects with impaired glucose tolerance patients (IGT) was also included in this study. These authors did not find statistically significant differences in the average blood glucose concentrations and time spent in hyperglycemia following the exercise [22]. In another study, they compared the effect on glucose levels after breakfast of a fixed volume of $60 \mathrm{~min}$ of moderate intensity aerobic exercise, carried out just before breakfast as a single bout on alternate days ("60 min alternate day" design), or subdivided in $30 \mathrm{~min}$ of exercise every day ("30 min daily" design) [23]. The study reports that during the first day the greater the volume, the higher the effect on blood glucose, i.e. blood glucose reduction was greater in the " $60 \mathrm{~min}$ alternate day" than in the " $30 \mathrm{~min}$ daily" design; however, during the second day a lower blood glucose was recorded in the "30 min daily" design. In both designs glucose concentrations were lower than those measured on a non-exercise day.

More recently, Figueira et al. [24] compared the effects of more vigorous aerobic vs combined training. They reported that blood glucose was similarly reduced during the sessions with both the exercise modalities, as compared to a non-exercise day, and that it returned to baseline levels about 3 hours after exercise.

As a whole, these data support the recommendation of performing at least $30 \mathrm{~min}$ of daily exercise, reported in the most authoritative guidelines for exercise prescription in subjects with type 2 diabetes, as a strategy to improve the daily glycemic control of these patients. Nevertheless, available data are limited and very heterogeneous. The reduction in glucose levels during a single bout of exercise appears quite different in these studies. These differences might be explained in part by differences in characteristics of the subjects, as well as the medication in use and/or caloric intake.

However, glucose control might be another relevant issue. In this regard, a previous study investigated the role of pre-exercise blood glucose levels of diabetic patients [25], either at fasting or at different time points in post-prandial conditions - up to 8-h after food ingestionby measuring capillary blood glucose before and immediately after a $60 \mathrm{~min}$ moderate intensity aerobic exercise. When exercise was performed in fasted conditions, glucose levels did not change if preexercise glucose was between $6-8 \mathrm{mmol} / \mathrm{l}$, but it significantly increased if pre-exercise glycemia was below, and decreased if it was above this interval. However, in post-prandial conditions most exercise sessions were associated with an $18-50 \%$ decrease in glucose levels, this value being associated with both the pre-exercise glucose value and the time interval between the meal and the onset of exercise [25].

While these aspects should be carefully considered in future studies, preliminary results suggest that differences in exercise type, volume and intensity, and also the duration of the interventions are likely to be relevant issues. In particular, it is interesting to note that aerobic training might be more effective than resistance training in reducing glucose levels during a single bout of exercise.

\section{Differences in the Acute Effect of Exercise on Glucose Control: Analysis of Blood Glucose Levels in the 24-48 h Periods Following Completion of the Exercise Session}

It is widely accepted that the metabolic effect of a single bout of exercise may persist for periods from 2-h to 48-h after cessation of 
Citation: Bacchi E, Negri C, Bonora E, Moghetti P (2013) Influence of Acute Bouts of Exercise on Blood Glucose in Type 2 Diabetic Patients, as Measured by Continuous Glucose Monitoring Systems. J Diabetes Metab 4: 311. doi:10.4172/2155-6156.1000311

Page 4 of 8

\begin{tabular}{|c|c|c|c|c|c|c|}
\hline \multirow{2}{*}{ Study } & \multirow{2}{*}{ Patients } & \multirow{2}{*}{$\begin{array}{l}\text { Design and type of } \\
\text { CGMS }\end{array}$} & \multirow{2}{*}{ Type of Exercise } & \multirow{2}{*}{ Diet } & \multicolumn{2}{|c|}{ Effect on blood glucose } \\
\hline & & & & & During exercise & After exercise \\
\hline $\begin{array}{l}\text { Praet et } \\
\text { al. } \\
2006 \text { [21] }\end{array}$ & $\begin{array}{l}11 \text { overweight } \\
\text { and obese } \\
\text { (males); } \\
\text { insulin treated }\end{array}$ & $\begin{array}{l}\text { 24-h before and } 24-\mathrm{h} \\
\text { after exercise } \\
\text { Day-time of ex: } 11.00 \\
\text { CGMS: microdialysis }\end{array}$ & $\begin{array}{l}\text { - RES ex ( } 50 \% 1 \mathrm{RM}) \text { plus } \\
\text { high-intensity interval ex: } \\
\text { whole-body warm-up; } \\
\text { two leg exercises, } 2 \text { set, } 10 \\
\text { rep; and } \\
\text { four } 30 \text {-s high- intensity } \\
\text { interval exercises on a } \\
\text { bicycle, alternated with } \\
60 \text {-s recovery }\end{array}$ & $\begin{array}{l}\text { Subjects asked to closely } \\
\text { match their daily nutritional } \\
\text { intake }\end{array}$ & $\begin{array}{l}\text { Blood glucose } \\
\downarrow R E S e x \text { vs } \\
\text { pre-ex }\end{array}$ & $\begin{array}{l}\text { Mean 24-h glucose } \\
\text { No difference } \\
\text { Glucose variability (CONGA) } \\
\text { No difference } \\
\text { Hyperglycemia (duration) } \\
\downarrow \text { day after ex } \\
\text { Hypoglycemia (duration) } \\
\text { No difference }\end{array}$ \\
\hline $\begin{array}{l}\text { Manders } \\
\text { et al. } \\
2006 \text { [28] }\end{array}$ & $\begin{array}{l}9 \text { overweight } \\
\text { (males); } \\
\text { non-insulin } \\
\text { treated }\end{array}$ & $\begin{array}{l}\text { 24-h after exercise } \\
\text { Day-time of ex: } 09.00 \\
\text { CGMS: microdialysis }\end{array}$ & $\begin{array}{l}\text { - Low-intensity ex: } 60 \mathrm{~min} \\
\text { of cycling } \\
\text { ( } 35 \% \text { Wmax); } \\
\text { - High-Intensity ex: } 60 \mathrm{~min} \\
\text { of cycling } \\
\text { ( } 70 \% \text { Wmax); } \\
\text { - Non-ex: seated for } 60 \\
\text { min }\end{array}$ & $\begin{array}{l}\text { Meals in pre-weighed } \\
\text { packages }\end{array}$ & - & $\begin{array}{l}\text { Mean 24-h glucose and AUC } \\
\downarrow \text { low-intensity ex vs non-ex } \\
\text { Hyperglycemia (duration, 24-h) } \\
\downarrow \text { low-intensity ex vs non-ex } \\
\text { Hyperglycemia (after dinner) } \\
\downarrow \text { low- and-high intensity ex vs non-ex }\end{array}$ \\
\hline $\begin{array}{l}\text { Van Dijk } \\
\text { et al. } 2011 \\
{[22]}\end{array}$ & $\begin{array}{l}30 \text { overweight } \\
\text { and obese } \\
\text { (males); } \\
\text { either insulin } \\
\text { treated or } \\
\text { non-insulin } \\
\text { treated }\end{array}$ & $\begin{array}{l}\text { 24-h after exercise } \\
\text { Day-time of ex: } 11.00 \\
\text { CGMS: microdialysis }\end{array}$ & $\begin{array}{l}\text { - AER ex: } 45 \text { min of cycling } \\
\text { ( } 50 \% \text { Wmax); } \\
\text { - RES ex: } 45 \text { min, upper } \\
\text { body ex, } 3 \text { set, } 10 \text { rep, } 20 \text { - } \\
40 \% \text { bodyweight; plus } \\
\text { lower body ex } 5 \text { set, } 10 \text { rep } \\
\text { at } 55-75 \% 1 \mathrm{RM} \text {; } \\
\text { - Non-ex: seated for } 45 \\
\text { min }\end{array}$ & $\begin{array}{l}\text { Meals in pre-weighed } \\
\text { packages }\end{array}$ & $\begin{array}{l}\text { Mean glucose } \\
\text { No difference } \\
\text { Hyperglycemia } \\
\text { (duration) } \\
\text { No difference }\end{array}$ & $\begin{array}{l}\text { Mean 24-h glucose } \\
\downarrow A E R \text { and RES ex vs non-ex } \\
\text { No difference AER ex vs RES ex } \\
\text { Hyperglycemia (duration, 24-h) } \\
\downarrow \text { AER and RES ex vs non-ex } \\
\text { No difference AER ex vs RES ex } \\
\text { Hyperglycemia (time periods) } \\
\downarrow \text { AER ex during afternoon and evening } \\
\downarrow R E S \text { ex during nocturnal period } \\
\downarrow \text { AER and RES ex during following } \\
\text { morning period } \\
\text { Hypoglycemia (duration, } 24-h) \\
\text { No difference } \\
\text { Hypoglycemia (time periods) } \\
\uparrow A E R \text { ex during evening }\end{array}$ \\
\hline $\begin{array}{l}\text { Van Dijk } \\
\text { et al. } 2012 \\
{[23]}\end{array}$ & $\begin{array}{l}30 \text { overweight } \\
\text { and obese } \\
\text { (males); } \\
\text { either insulin } \\
\text { treated or } \\
\text { non-insulin- } \\
\text { treated }\end{array}$ & $\begin{array}{l}\text { 48-h after exercise } \\
\text { Day-time of ex: } 10.00 \\
\text { (after breakfast) } \\
\text { CGMS: microdialysis }\end{array}$ & $\begin{array}{l}\text { - AER ex "60": } 60 \text { min of } \\
\text { cycling ( } 50 \% \text { Wmax) the } \\
\text { first day; } \\
\text { - AER ex " } 30+30 ": 30 \text { min } \\
\text { of cycling ( } 50 \% \text { Wmax) } \\
\text { each day; } \\
\text { Non-ex: habitual sedentary } \\
\text { condition }\end{array}$ & $\begin{array}{l}\text { Meals in pre-weighed } \\
\text { packages }\end{array}$ & $\begin{array}{l}\text { Mean glucose } \\
\text { - First day: } \\
\downarrow \text { both AER ex vs } \\
\text { non-ex; } \\
\downarrow \text { AERex "60" vs } \\
\text { AERex " } 30+30 " . \\
\text { - Second day: } \\
\downarrow \text { both AER ex vs } \\
\text { non-ex; } \\
\downarrow \text { AERex “ } 30+30 " \\
\text { vs AERex "60". }\end{array}$ & $\begin{array}{l}\text { Mean 24-h glucose } \\
\downarrow \text { both AER ex on the first and second day } \\
\text { Hyperglycemia (\% of the time) } \\
\downarrow \text { both AER ex on the first and second day }\end{array}$ \\
\hline $\begin{array}{l}\text { Van Dijk } \\
\text { et al. } 2013 \\
{[29]}\end{array}$ & $\begin{array}{l}60 \text { overweight } \\
\text { and obese } \\
\text { (males); } \\
\text { either insulin } \\
\text { treated or } \\
\text { non-insulin- } \\
\text { treated }\end{array}$ & $\begin{array}{l}\text { 24-h after exercise } \\
\text { Day-time of ex: } 10.00 \\
\text { (after breakfast) } \\
\text { CGMS: microdialysis }\end{array}$ & $\begin{array}{l}\text { - AER ex: } \\
45-60 \text { min of cycling (35- } \\
50 \% \text { Wmax); } \\
\text { - Non-ex: seated for } 45- \\
60 \text { min }\end{array}$ & $\begin{array}{l}\text { Meals in pre-weighed } \\
\text { packages }\end{array}$ & - & $\begin{array}{l}\text { Mean 24-h glucose } \\
\downarrow \text { AER ex in both insulin and non-insulin } \\
\text { treated; } \\
\text { Hyperglycemia (duration, 24-h) } \\
\downarrow \text { AER ex } \\
\text { Hypoglycemia (duration, 24-h) } \\
\text { No difference } \\
\text { Glucose variability (CONGA) } \\
\downarrow \text { AER ex }\end{array}$ \\
\hline $\begin{array}{l}\text { Van Dijk } \\
\text { et al. } 2013 \\
{[30]}\end{array}$ & $\begin{array}{l}20 \text { overweight } \\
\text { and obese } \\
\text { (males); } \\
\text { non-insulin } \\
\text { treated }\end{array}$ & $\begin{array}{l}\text { 72-h, exercise on the } \\
\text { second day } \\
\text { Day-time of ex: } \\
-9.15 \text { for AER-ex } \\
\text { (after breakfast); } \\
-9.15,12.15 \text {, and } \\
16.45 \text { for DLA (after } \\
\text { the main meals) } \\
\text { CGMS: microdialysis }\end{array}$ & $\begin{array}{l}\text { - AER ex: } \\
\text { 45-min of cycling } \\
\text { ( } 6 \text { METs) } \\
\text { - DLA: three 15-min bouts } \\
\text { of postmeal strolling ( } 3 \\
\text { METs) } \\
\text { - Non-ex: habitual } \\
\text { sedentary condition }\end{array}$ & $\begin{array}{l}\text { Standardized } \\
\text { dietary conditions }\end{array}$ & - & $\begin{array}{l}\text { Mean 24-h glucose } \\
\downarrow A E R \text { ex } \\
\text { Hyperglycemia (duration, 24-h) } \\
\downarrow A E R \text { ex } \\
\text { Post-prandial glucose } \\
\downarrow A E R \text { ex, at each meal } \\
\downarrow A E R \text { and DLA, for the cumulative } \\
\text { glucose response to meals }\end{array}$ \\
\hline $\begin{array}{l}\text { Bacchi } \\
\text { et al. } \\
2012 \text { [20] }\end{array}$ & $\begin{array}{l}25 \text { overweight } \\
\text { and obese } \\
\text { (both males } \\
\text { and females); } \\
\text { non-insulin } \\
\text { treated }\end{array}$ & $\begin{array}{l}\text { 48-h during and after } \\
\text { exercise } \\
\text { Day-time of ex: } 18.30 \\
\text { CGMS: glucose } \\
\text { oxidase }\end{array}$ & $\begin{array}{l}- \text { AER ex }(n=13): 60 \mathrm{~min}, \\
60-65 \% \text { HRR; } \\
- \text { RES ex }(n=12): 60 \mathrm{~min}, \\
9 \text { ex, } 3 \text { series, } 10 \\
\text { repetitions at } 70-80 \% \\
1 \mathrm{RM} ; \\
\text {-Non-ex: corresponding } \\
\text { time periods in non-ex day }\end{array}$ & $\begin{array}{l}\text { Subjects asked to closely } \\
\text { match their daily nutritional } \\
\text { intake }\end{array}$ & $\begin{array}{l}\text { Glucose AUC } \\
\downarrow A E R \text { ex vs RES } \\
\text { ex and Non-ex }\end{array}$ & $\begin{array}{l}\text { 24-h glucose AUC } \\
\text { No difference } \\
\text { 48-h glucose AUC } \\
\text { No difference } \\
\text { Nocturnal glucose AUC } \\
\downarrow \text { AER ex vs Non-ex } \\
\text { Hyperglycemia (HBGI) } \\
\text { No difference } \\
\text { Hypoglycemia (LBGI) } \\
\uparrow A E R \text { ex during nocturnal period vs Non- } \\
\text { ex day }\end{array}$ \\
\hline
\end{tabular}


Citation: Bacchi E, Negri C, Bonora E, Moghetti P (2013) Influence of Acute Bouts of Exercise on Blood Glucose in Type 2 Diabetic Patients, as Measured by Continuous Glucose Monitoring Systems. J Diabetes Metab 4: 311. doi:10.4172/2155-6156.1000311

Page 5 of 8

\begin{tabular}{|c|c|c|c|c|c|c|}
\hline $\begin{array}{l}\text { Figueira } \\
\text { et al. } 2013 \\
{[24]}\end{array}$ & $\begin{array}{l}14 \text { overweight } \\
\text { and obese } \\
\text { (both males } \\
\text { and females); } \\
\text { non-insulin } \\
\text { treated }\end{array}$ & $\begin{array}{l}\text { 24-h before and 48-h } \\
\text { after exercise } \\
\text { Day-time of ex:12.00 } \\
\text { CGMS: glucose } \\
\text { oxidase }\end{array}$ & $\begin{array}{l}\text { - AER ex: } 40 \text { min at } 70 \% \\
\text { peak heart rate } \\
\text { - COMB ex: } 20 \text { min at } 70 \% \\
\text { peak heart rate and } 4 \text { RES } \\
\text { exercises, } 3 \text { sets of } 12 \text { rep } \\
\text { at } 65 \% 1 \mathrm{RM}\end{array}$ & $\begin{array}{l}\text { Subjects asked to closely } \\
\text { match their daily nutritional } \\
\text { intake }\end{array}$ & $\begin{array}{l}\text { Blood glucose } \\
\downarrow \text { AER and } \\
\text { COMB ex vs } \\
\text { pre-ex }\end{array}$ & $\begin{array}{l}\text { 24-h glucose AUC } \\
\text { No difference } \\
\text { 48-h glucose AUC } \\
\text { No difference } \\
\text { Hyperglycemia (episodes) } \\
\text { No difference between AER and COMB } \\
\text { ex and vs pre-ex } \\
\text { Glucose variability (MAGE, variance, CV } \\
\text { and SD) } \\
\downarrow C O M B \text { ex vs pre-ex }\end{array}$ \\
\hline $\begin{array}{l}\text { Mikus et } \\
\text { al. } 2012 \\
{[31]}\end{array}$ & $\begin{array}{l}13 \text { overweight } \\
\text { and obese } \\
\text { (both males } \\
\text { and females); } \\
\text { non-insulin } \\
\text { treated }\end{array}$ & $\begin{array}{l}\text { 72-h before exercise, } \\
\text { and } 72-\mathrm{h} \text { in the last } \\
3 \text { days of seven } \\
\text { consecutive days of } \\
\text { training } \\
\text { Day-time of ex: not } \\
\text { specified } \\
\text { CGMS: glucose } \\
\text { oxidase }\end{array}$ & $\begin{array}{l}\text {-AER ex: } 60 \mathrm{~min},(20 \mathrm{~min} \\
\text { treadmill walking, } 20 \mathrm{~min} \\
\text { stationary cycling, } 20 \mathrm{~min} \\
\text { treadmill walking) at } 60- \\
75 \% \text { HRR } \\
\text {-Non-ex: habitual } \\
\text { sedentary condition }\end{array}$ & $\begin{array}{l}\text { Standardized dietary } \\
\text { conditions. Additional } \\
\text { snacks during training days } \\
\text { matched for exercise energy } \\
\text { cost }\end{array}$ & - & $\begin{array}{l}\text { Mean 24-h glucose } \\
\text { No difference } \\
\text { Hyperglycemia (duration, 24-h) } \\
\downarrow \text { AER ex } \\
\text { Post-prandial glucose } \\
\downarrow \text { AER ex } \\
\text { Hypoglycemia (duration, 24-h) } \\
\downarrow \text { AER ex } \\
\text { Glucose variability (glucose excursions) } \\
\downarrow \text { AER ex }\end{array}$ \\
\hline $\begin{array}{l}\text { Gillen et } \\
\text { al. } 2012 \\
{[35]}\end{array}$ & $\begin{array}{l}7 \text { overweight } \\
\text { and obese } \\
\text { (gender not } \\
\text { specified); } \\
\text { non-insulin } \\
\text { treated }\end{array}$ & $\begin{array}{l}\text { 24-h after exercise } \\
\text { Day-time of ex: } 08.00 \\
\text { (1.5 h after breakfast) } \\
\text { CGMS: glucose } \\
\text { oxidase }\end{array}$ & $\begin{array}{l}\text { - High intensity interval } \\
\text { ex: ten } 60 \text {-s cycling efforts } \\
\text { at } 89 \% \text { Wmax, alternated } \\
\text { with } 60 \text {-s recovery; } \\
\text {-Non-ex: corresponding } \\
\text { time periods in non-ex day }\end{array}$ & Individualized diets & - & $\begin{array}{l}\text { Mean 24-h glucose } \\
\text { No difference } \\
\text { Hyperglycemia (duration, 24-h) } \\
\downarrow \text { HIT ex } \\
\text { Post-prandial glucose } \\
\downarrow \text { HIT ex }\end{array}$ \\
\hline $\begin{array}{l}\text { Oberlin et } \\
\text { al. 2013 } \\
{[32]}\end{array}$ & $\begin{array}{l}9 \text { obese (both } \\
\text { males and } \\
\text { females); } \\
\text { non-insulin } \\
\text { treated }\end{array}$ & $\begin{array}{l}\text { 48-h after exercise } \\
\text { Day-time of ex: } 06.30 \\
\text { CGMS: glucose } \\
\text { oxidase }\end{array}$ & $\begin{array}{l}\text {-AER ex: } 60 \mathrm{~min},(20 \mathrm{~min} \\
\text { treadmill walking, } 20 \mathrm{~min} \\
\text { stationary cycling, } 20 \mathrm{~min} \\
\text { treadmill walking) at } 60- \\
75 \% \text { HRR } \\
\text {-Non-ex: habitual } \\
\text { sedentary condition }\end{array}$ & $\begin{array}{l}\text { Standardized } \\
\text { dietary conditions }\end{array}$ & - & $\begin{array}{l}\text { Mean 24-h glucose } \\
\downarrow \text { AER ex during the first day } \\
\text { Post-prandial glucose } \\
\downarrow \text { AER ex for the cumulative glucose } \\
\text { response to meals over the two days }\end{array}$ \\
\hline
\end{tabular}

AER: Aerobic Training; AUC: Area Under The Curve; COMB: Combined Aerobic and Resistance Exercise Training; CONGA: Continuous Overall Net Glycemic Action; CV: Coefficient of Variation; DLA: Daily Living Activities; ex: Exercise; HBGI: High Blood Glucose Index; HIT: High-Intensity Interval Training; HRR: Heart Rate Reserve; LBGI: Low Blood Glucose Index; MAGE: Mean Amplitude of Glycemic Excursion; Rep: Repetitions; RES: Resistance Training; SD: Standard Deviation; W:Watt; Wmax: Maximal Watt; $\downarrow$ :Significantly Reduced; $\uparrow:$ Significantly Increased

Table 1: Summary of studies assessing the effect of a single bout of exercise on blood glucose in type 2 diabetes subjects by CGMS.

exercise [7-9], both in diabetic and non-diabetic subjects. This statement is based on studies which assessed the effect of exercise on glucose levels, as measured by finger-stick blood glucose or by laboratory assay at standardized time point, and/or insulin sensitivity. Our knowledge of the possible differences associated with the characteristics of exercise is still very limited, and guidelines do not indicate whether in diabetic patients diet and medication adaptation linked to exercise should differ according to any specific characteristics of training.

CGMS may be very useful in providing clinical information about the short-term effect of a single bout of exercise on blood glucose. Time spent in hyperglycemia and/or hypoglycaemia may be accurately assessed for several days after each exercise session in free living conditions, potentially allowing the physician to obtain important information for optimal use of exercise in diabetic patients.

A recent metaanalysis of the effects of exercise on blood glucose levels, as measured by CGMS in subjects with type 2 diabetes, concluded that exercise significantly decreased average glucose concentrations $(-0.8 \mathrm{mmol} / \mathrm{L})$ and daily time spent in hyperglycemia in these patients, whereas fasting glucose levels and daily time spent in hypoglycaemia were not significantly affected [26]. A previous systematic review, carried out considering data collected before the CGMS age, had also reported that fasting glycemia was not consistently reduced following exercise [27]. However, no reliable information about the other outcomes reported by the metaanalysis was previously available. Nevertheless, we must be aware that even this metaanalysis was based on the results of a few, small-size and heterogeneous studies, differing in terms of type and intensity of exercise, exercise session daytime and duration of intervention.

To the best of our knowledge, eleven studies have assessed the impact of a single session of exercise on glucose concentrations in the following 24 - to 48 -h period, with discordant results. In particular, six of these studies reported significant changes in the average glucose levels during the 24-h period following a single bout of exercise while five other studies did not.

Manders et al. [28] assessed the impact of a single bout of low- or high-intensity aerobic exercise on the prevalence of hyperglycemia throughout the 24-h post-exercise period, in 9 sedentary males with type 2 diabetes. Interestingly, they found that the low-intensity aerobic exercise, but not the high-intensity exercise, was able to reduce the average glucose levels over the following 24 hours $v s$ the control non-exercise day. More recently, the same group reported a similar reduction of blood glucose levels after 24 -h and 48-h of either daily or alternate day moderate aerobic exercise, in both insulin and noninsulin treated type 2 diabetic patients [23]. Again, the same authors, in another study [29], assessed the effect of a single bout of moderateintensity exercise on the subsequent 24 -h glycemic profile in 60 insulin or non-insulin treated subjects with type 2 diabetes. In this study they examined whether the individual responses to exercise were related to subjects' baseline characteristics. These authors found that average 24-h blood glucose concentrations were lower than in a control nonexercise day. Moreover, the reduction after exercise in average glucose concentrations correlated significantly with patients' HbAlc level, 
but not with age, body mass index, diabetes duration or maximal watt. More recently, this group also compared the effect of $45 \mathrm{~min}$ of moderate intensity aerobic exercise with an equivalent time spent in three short bouts of low-intensity daily life activities [30]. In this study, aerobic exercise only was effective in lowering average glucose levels.

Mikus et al. [31], in a group of sedentary diabetic patients, assessed by CGMS the glucose profiles over three days of habitual life activities and in the last three days of a seven-day period in which $60 \mathrm{~min}$ of daily vigorous aerobic training was introduced. They reported that average glucose levels in the 24 -h period following these exercise sessions were not different from values measured during habitual sedentary conditions. However, post-prandial glucose and duration of hyperglycemia were significantly lowered after exercise. The same group [32] recently explored the 48 -h effects of a single bout of this protocol of vigorous aerobic exercise, performed early in the morning. In this latter study, average glucose was significantly reduced during the first 24-h period. In addition, the cumulative glucose response to all meals over the two days was also reduced, whereas analysis of glucose responses to each meal showed that exercise especially reduced the postprandial values of lunch on the first day [32]

Karstoft et al. [33], in 27 diabetic subjects randomized to a continuous walking training group, an interval walking training group - matched in terms of mean intensity of exercise and overall energy expenditure - or a non-exercise control group for 4 months, reported that interval training was superior to moderate intensity exercise in lowering average daily glucose levels. Consistently, Little et al. [34] reported lowered average 24 -h glucose and cumulative postprandial glucose levels, as compared to pre-training values, after a total of six supervised sessions of high intensity interval training over two weeks. However, in both these studies post-intervention CGMS measurements were performed 48-72 hours after completion of the training program. Therefore these data cannot be used to analyze the acute effect of exercise, although the may reflect the long-term metabolic changes induced by regular physical activity. Interestingly, in a small study carried out on seven of the subjects investigated by Little et al. [34], postprandial glucose and time spent in hyperglycemia in the 24-h period following the first bout of high intensity interval training were both significantly reduced, although average 24 -h glucose levels were not significantly reduced [35].

Praet et al. [21] did not show any significant reduction in mean blood glucose concentrations during the 24-h period following exercise, in comparison with a non-exercise day. Similarly, in our study [20] we did not detect a significant change in blood glucose AUC over a 48 -h period following a session of moderate resistance exercise, in a group of trained diabetic patients performing regular physical activity. Similar findings were reported by Figueira et al. [24] after a session of more vigorous exercise, either combined or aerobic alone.

Cauza et al. [36], in a 4-month intervention study in which participants were randomized to strength or endurance training, reported that strength training led to a significant decrease in average glucose concentrations, as measured by CGMS, while aerobic training did not. However, post-intervention measurements were performed several days after patients had completed the training programme and therefore these data only explored the long-term effect of exercise.

Some of these studies have also specifically investigated the effect of a single bout of exercise on the prevalence of hyperglycemia and/ or hypoglycaemia. Van Dijk et al. [22], in a sample of 30 subjects with type 2 diabetes, showed that time spent in hyperglycemia over the $24-\mathrm{h}$ period after a single bout of exercise was less with either aerobic or resistance training, as compared with a non-exercise day. The same group [28] reported better results with low-intensity aerobic exercise, than with high-intensity aerobic exercise. In agreement with these findings, the same authors found a reduction in the prevalence of hyperglycemia after an acute bout of leg resistance exercise training followed by high-intensity interval exercise [21], as well as after daily or alternate day moderate intensity aerobic exercise, as compared to nonexercise. Interestingly, $45 \mathrm{~min}$ of moderate aerobic exercise was also better than an equivalent amount of time spent in low-intensity daily life activities in reducing hyperglycemia duration and postprandial glucose levels, although cumulative glucose response to all main meals was also significantly lowered by daily life activities [30]. Mikus et al. as well, reported reduced duration of daily time spent in hyperglycemia and lowered postprandial glucose levels after moderate intensity aerobic exercise [31]

Conversely, Bacchi et al. [20] did not show a decrease in HBGI, a parameter which summarizes both duration and extent of hyperglycemia, in the 24-h period after a single bout of either aerobic or resistance exercise. Consistent with these findings, Figueira et al. [24] did not detect differences in hyperglycemia episodes in the 24 -h period following a session of aerobic or combined exercise, as compared with a non-exercise day.

Five studies focused on the risk for hypoglycaemia [11-13,17,31], after different types of exercise. Praet et al. [21] and Van Dijk et al. [29] did not find changes in the duration or the number of episodes of hypoglycaemia, respectively, during the 24-h time frame following exercise. Conversely, Bacchi et al. [20] and Van Dijk et al. [22] reported different findings. Interestingly, in the first study, aimed at comparing the effect of aerobic or resistance exercise, an increased risk for hypoglycaemia, as measured by the LBGI - which summarizes both the extent and duration of hypoglycaemia - was reported during the nocturnal period following aerobic training but not after resistance training [20]. In the second study, which also compared aerobic and resistance exercise, the time spent in hypoglycaemia was similarly increased after aerobic exercise, but this phenomenon occurred earlier, in the evening [22]. A likely explanation for the difference in the time frame in which hypoglycaemia occurred is the time of day of the exercise sessions, which was in the late afternoon in our study vs in the late morning in the van Dijk study. Thus in both studies, increased risk for hypoglycaemia occurred with a similar time lag after the exercise sessions. This information could be important, as these findings suggest that particular attention should be paid to the risk of hypoglycaemia 6-12 $\mathrm{h}$ after moderate intensity aerobic exercise. However, at odds with these findings, Mikus et al. [31] found a reduced time spent in hypoglycaemia after moderate intensity aerobic exercise. This latter study did not specify the exercise session daytime and did not report when this improvement was observed, precluding further analysis of these findings.

A few studies investigated by CGMS the effects of exercise in terms of glucose variability, which is a risk factor for all-cause mortality in type 2 diabetic patients [37]. Praet et al. reported that glucose variability, as measured by continuous overall net glycemic action (CONGA), was not significantly different in the 24 hours preceding and following combined resistance and high-intensity interval exercise [21]. Conversely, Mikus et al. who compared glucose excursions over three days of habitual activity and during the final three days of a seven- 
day aerobic exercise training program in previously sedentary patients with well controlled type 2 diabetes, reported that glycaemic variability was attenuated during the training period [31]. More recently, Figueira et al. estimated glucose variability by several conventional (glucose standard deviation, glucose variance, mean amplitude of glycemic excursions, and glucose coefficient of variation), and non-conventional analyses (spectral and symbolic analysis) in diabetic patients performing a single bout of either aerobic or combined exercise [24]. In this study, non-conventional analysis suggested reduction of glucose variability in the 24-h period following combined exercise, whereas conventional measures did not show differences vs. the non-exercise day.

As a whole, it appears from these findings that it may be still problematic to accurately foresee the expected blood glucose changes during and following a single bout of different types of exercise in diabetic patients. Type 2 diabetes is a heterogeneous disease and the different medications used for diabetes treatment interact differently with the metabolic effects of physical activity. Moreover, as reported above, glucose control itself may affect the blood glucose response to exercise [25]. A possible explanation for these discrepancies also relies in the different training status of diabetic subjects, sedentary vs. trained.

Bearing in mind the limitations of available data, current information suggests that moderate intensity exercise may cause greater blood glucose reduction than either low-intensity or high intensity exercise [28,30], although some data challenge this conclusion [33]. Differences in the balance between the opposite effects of exerciseinduced glucose utilization and counterregulatory hormone-induced glucose production possibly underlie this phenomenon.

Similarly, as regards comparison of aerobic and resistance exercise, results are still limited and controversial. Whereas van Dijk et al. in sedentary patients included in a short-term study, concluded that there were very similar reductions in glucose levels over the 24 hour period following a single bout of aerobic or resistance exercise [22], Bacchi et al. in trained patients participating in a 4-month intervention study, reported greater glucose reduction after the aerobic exercise, during both the exercise session and the nocturnal period following exercise [20]. These discrepancies could indicate a complex interaction between exercise characteristics and duration of training in terms of effect of exercise on glucose levels. Nevertheless, a greater reduction of glucose concentrations with increased time spent in hypoglycemia after aerobic exercise was also seen in the van Dijk study, if we consider the 6 to 12 -h period after exercise [22].

Nonetheless, these preliminary findings indicate the urgent need for larger studies, now made possible by the CGMS technology, designed to clarify this very important clinical issue. Future research should take into account a number of factors potentially affecting glucose response to exercise in diabetic patients, such as the characteristics of exercise (frequency, intensity, duration and type), training status of the patients, metabolic control, antidiabetic therapy, diet composition, and distance of exercise sessions from the meals and timing of exercise bouts.

\section{Summary}

Recent studies carried out by using the CGMS, which allows the continuous recording of blood glucose levels for several days in real life conditions, have raised great interest concerning the possible differences of the acute effect of a single bout of exercise on blood glucose levels of individuals with type 2 diabetes. In particular, differences between aerobic vs. resistance and combined exercise and between low-intensity vs high-intensity exercise have been reported.
These differences may influence diet and hypoglycemic medication adaptation to exercise used in diabetic patients. However, there are only a few, small and heterogeneous studies on this topic, and their results are to some extent discordant, limiting any conclusions. These studies included either trained or untrained diabetic patients, and this difference might contribute to the discrepant findings.

Further research on this issue is needed before we can reach clear conclusions, which are crucial to our understanding of how to optimize the use of exercise in people with type 2 diabetes. In particular, the role of differences in frequency, duration, intensity, type and timing of exercise should be thoroughly investigated. Hopefully, this information will assist clinicians and exercise specialists in designing personalized exercise programmes and strategies aimed at optimally improving glucose control of type 2 diabetic patients, limiting the risk for hypoglycaemia.

\section{References}

1. Boulé NG, Haddad E, Kenny GP, Wells GA, Sigal RJ (2001) Effects of exercise on glycemic control and body mass in type 2 diabetes mellitus: a meta-analysis of controlled clinical trials. JAMA 286: 1218-1227.

2. Colberg SR, Sigal RJ, Fernhall B, Regensteiner JG, Blissmer BJ, et al. (2010) Exercise and type 2 diabetes: the American College of Sports Medicine and the American Diabetes Association: joint position statement. Diabetes Care 33: e147-167.

3. Bacchi E, Negri C, Zanolin ME, Milanese C, Faccioli N, et al. (2012) Metabolic effects of aerobic training and resistance training in type 2 diabetic subjects: a randomized controlled trial (the RAED2 study). Diabetes Care 35: 676-682.

4. Bacchi E, Negri C, Targher G, Faccioli N, Lanza M, et al. (2013) Both resistance training and aerobic training reduce hepatic fat content in type 2 diabetic subjects with nonalcoholic fatty liver disease (the RAED2 randomized trial). Hepatology 58: 1287-1295

5. Boulé NG, Kenny GP, Haddad E, Wells GA, Sigal RJ (2003) Meta-analysis of the effect of structured exercise training on cardiorespiratory fitness in Type 2 diabetes mellitus. Diabetologia 46: 1071-1081.

6. Chou $\mathrm{CH}$, Hwang CL, Wu YT (2012) Effect of exercise on physical function, daily living activities, and quality of life in the frail older adults: a meta-analysis. Arch Phys Med Rehabil 93: 237-244.

7. Devlin JT, Hirshman M, Horton ED, Horton ES (1987) Enhanced periphera and splanchnic insulin sensitivity in NIDDM men after single bout of exercise. Diabetes 36: 434-439.

8. Mikines KJ, Sonne B, Farrell PA, Tronier B, Galbo H (1988) Effect of physical exercise on sensitivity and responsiveness to insulin in humans. Am J Physio 254: E248-259.

9. Wojtaszewski JF, Hansen BF, Gade, Kiens B, Markuns JF, et al. (2000) Insulin signaling and insulin sensitivity after exercise in human skeletal muscle. Diabetes 49: 325-331.

10. Suh SH, Paik IY, Jacobs K (2007) Regulation of blood glucose homeostasis during prolonged exercise. Mol Cells 23: 272-279.

11. Figueira FR, Umpierre D, Ribeiro JP, Tetelbom PS, Henn NT, et al. (2012) Accuracy of continuous glucose monitoring system during exercise in type 2 diabetes. Diabetes Res Clin Pract 98: e36-39.

2. Kovatchev B, Anderson S, Heinemann L, Clarke W (2008) Comparison of the numerical and clinical accuracy of four continuous glucose monitors. Diabetes Care 31: 1160-1164

13. Sigal RJ, Kenny GP, Boulé NG, Wells GA, Prud'homme D, et al. (2007) Effects of aerobic training, resistance training, or both on glycemic control in type 2 diabetes: a randomized trial. Ann Intern Med 147: 357-369.

14. Church TS, Blair SN, Cocreham S, Johannsen N, Johnson W, et al. (2010) Effects of aerobic and resistance training on hemoglobin A1c levels in patients with type 2 diabetes: a randomized controlled trial. JAMA 304: 2253-2262.

15. Scuffi C, Lucarelli F, Valgimigli F (2012) Minimizing the impact of time lag variability on accuracy evaluation of continuous glucose monitoring systems. J Diabetes Sci Technol 6: 1383-1391 
Citation: Bacchi E, Negri C, Bonora E, Moghetti P (2013) Influence of Acute Bouts of Exercise on Blood Glucose in Type 2 Diabetic Patients, as Measured by Continuous Glucose Monitoring Systems. J Diabetes Metab 4: 311. doi:10.4172/2155-6156.1000311

Page 8 of 8

16. Diabetes Research In Children Network (Direcnet) Study Group, Buckingham BA, Kollman C, Beck R, Kalajian A, et al. (2006) Evaluation of factors affecting CGMS calibration. Diabetes Technol Ther 8: 318-325.

17. Kumareswaran K, Elleri D, Allen JM, Caldwell K, Nodale M, et al. (2013) Accuracy of continuous glucose monitoring during exercise in type 1 diabetes pregnancy. Diabetes Technol Ther 15: 223-229.

18. McGarraugh GV, Clarke WL, Kovatchev BP (2010) Comparison of the clinical information provided by the FreeStyle Navigator continuous interstitial glucose monitor versus traditional blood glucose readings. Diabetes Technol Ther 12 365-371.

19. Iscoe KE, Davey RJ, Fournier PA (2012) Is the response of continuous glucose monitors to physiological changes in blood glucose levels affected by sensor life? Diabetes Technol Ther 14: 135-142.

20. Bacchi E, Negri C, Trombetta M, Zanolin ME, Lanza M, et al. (2012) Differences in the acute effects of aerobic and resistance exercise in subjects with type 2 diabetes: results from the RAED2 Randomized Trial. PLoS One 7: e49937.

21. Praet SF, Manders RJ, Lieverse AG, Kuipers H, Stehouwer CD, et al. (2006) Influence of acute exercise on hyperglycemia in insulin-treated type 2 diabetes. Med Sci Sports Exerc 38: 2037-2044.

22. van Dijk JW, Manders RJ, Tummers K, Bonomi AG, Stehouwer CD, et al (2012) Both resistance- and endurance-type exercise reduce the prevalence of hyperglycaemia in individuals with impaired glucose tolerance and in insulintreated and non-insulin-treated type 2 diabetic patients. Diabetologia 55: 1273 1282.

23. Van Dijk JW, Tummers K, Stehouwer CD, Hartgens F, van Loon LJ (2012) Exercise therapy in type 2 diabetes: is daily exercise required to optimize glycemic control? Diabetes Care 35: 948-954.

24. Figueira FR, Umpierre D, Casali KR, Tetelbom PS, Henn NT, et al. (2013) Aerobic and combined exercise sessions reduce glucose variability in type 2 diabetes: crossover randomized trial. PLoS One 8: e57733.

25. Gaudet-Savard T, Ferland A, Broderick TL, Garneau C, Tremblay A, et al (2007) Safety and magnitude of changes in blood glucose levels following exercise performed in the fasted and the postprandial state in men with type 2 diabetes. Eur J Cardiovasc Prev Rehabil 14: 831-836.

26. Macleod SF, Terada T, Chahal BS, Boulé NG (2013) Exercise lowers postprandial glucose but not fasting glucose in type 2 diabetes: a meta-analysis of studies using continuous glucose monitoring. Diabetes Metab Res Rev 29 : $593-603$.
27. Thomas DE, Elliott EJ, Naughton GA (2006) Exercise for type 2 diabetes mellitus. Cochrane Database Syst Rev : CD002968.

28. Manders RJ, Van Dijk JW, van Loon LJ (2010) Low-intensity exercise reduces the prevalence of hyperglycemia in type 2 diabetes. Med Sci Sports Exerc 42 219-225.

29. Van Dijk JW, Manders RJ, Canfora EE, Mechelen WV, Hartgens F, et al. (2013) Exercise and 24-h glycemic control: equal effects for all type 2 diabetes patients? Med Sci Sports Exerc 45: 628-635

30. van Dijk JW, Venema M, van Mechelen W, Stehouwer CD, Hartgens F, et al. (2013) Effect of moderate-intensity exercise versus activities of daily living on 24-hour blood glucose homeostasis in male patients with type 2 diabetes. Diabetes Care 36: 3448-3453.

31. Mikus CR, Oberlin DJ, Libla J, Boyle LJ, Thyfault JP (2012) Glycaemic control is improved by 7 days of aerobic exercise training in patients with type 2 diabetes. Diabetologia 55: 1417-1423.

32. Oberlin DJ, Mikus CR, Kearney ML, Hinton PS, Manrique C, et al. (2013) One Bout of Exercise Alters Free-Living Postprandial Glycemia in Type 2 Diabetes. Med Sci Sports Exerc.

33. Karstoft K, Winding K, Knudsen SH, Nielsen JS, Thomsen C, et al. (2013) The effects of free-living interval-walking training on glycemic control, body composition, and physical fitness in type 2 diabetic patients: a randomized, controlled trial. Diabetes Care 36: 228-236.

34. Little JP, Gillen JB, Percival ME, Safdar A, Tarnopolsky MA, et al. (2011) Lowvolume high-intensity interval training reduces hyperglycemia and increases muscle mitochondrial capacity in patients with type 2 diabetes. J Appl Physio (1985) 111: 1554-1560.

35. Gillen JB, Little JP, Punthakee Z, Tarnopolsky MA, Riddell MC, et al. (2012) Acute high-intensity interval exercise reduces the postprandial glucose response and prevalence of hyperglycaemia in patients with type 2 diabetes. Diabetes Obes Metab 14: 575-577.

36. Cauza E, Hanusch-Enserer U, Strasser B, Kostner K, Dunky A, et al. (2005) Strength and endurance training lead to different post exercise glucose profiles in diabetic participants using a continuous subcutaneous glucose monitoring system. Eur J Clin Invest 35: 745-751.

37. Muggeo M, Zoppini G, Bonora E, Brun E, Bonadonna RC, et al. (2000) Fasting plasma glucose variability predicts 10 -year survival of type 2 diabetic patients: the Verona Diabetes Study. Diabetes Care 23: 45-50. 